\title{
Two Cultures of Nanotechnology?
}

\author{
Bernadette Bensaude-Vincent
}

\begin{abstract}
Although many active scientists deplore the publicity about Drexler's futuristic scenario, I will argue that the controversies it has generated are very useful, at least in one respect. They help clarify the metaphysical assumptions underlying nanotechnologies, which may prove very helpful for understanding their public and cultural impact. Both Drexler and his opponents take inspiration from living systems, which they both describe as machines. However there is a striking contrast in their respective views of molecular machineries. This paper based on semipopular publications is an attempt to characterize the rival models of nanomachines and to disentangle the worldviews underpinning the uses of biological reference on both sides. Finally, in an effort to point out the historical roots of the contrast in the concepts of nanomachines, I raise the question of a divide between two cultures of nanotechnology.
\end{abstract}

Keywords: nanotechnology, self-assembly, molecular assembler, biomimetism, mechanism, dynamism.

\section{Introduction}

Over the past decade, Eric Drexler's successful volume Engines of Creation (1986) and the debates generated by its futuristic visions have been prominent in drawing public attention toward nanotechnology. Most scientists active in the field think that too much attention has been paid to this debate and they try to distance their own 'serious' research programs from Drexler's unrealistic scenario. At least the rejection of Drexler's rhetoric acts as a unifying principle in the otherwise heterogeneous crowd of scientists involved in nano-initiatives.

However as with many controversies in science, debates about Drexler's universal assemblers and the grey goo scenario have been extremely profitable as long as they helped clarify the philosophical assumptions underlying projects of nanoscience. ${ }^{1}$ Without claiming that the future of nanotechnology hinges on such debates, I will argue that they enlighten the public about the cultural roots and cultural projects of nanoscientists and engineers. In this respect, it is equally important to point out convergences and divergences between Drexler and his followers on one side and chemists such as Richard 
Smalley and George Whitesides who criticized Drexler's views of universal assemblers on the other side.

Drexler and his opponents share a common interest in biological systems. Already in Richard Feynman's almost legendary prophecy, there was a quick reference to biological material, where enormous amounts of information could be stored in exquisitely small spaces. Since 1959 and the early days of molecular biology, chemists, materials scientists and engineers have intensified and diversified their references to biology, even before the term 'nanotechnology' was coined. Bio-inspirations prevailed when the 'bottom-up' approach, the design of structures molecule by molecule (rather than atom by atom) became one of the major goals of nanotechnology. In contrast to the structures usually designed by engineers at the macrolevel, biomaterials are built from bottom up. Life operates by bonding atoms or groups of atoms instead of by carving a structure from raw materials. The convergence of nanotechnologies and biotechnologies is rooted in the claim that bio is nano', that biomaterials are structured from bottom up.

It is not my purpose to discuss the validity of such claims through a comparison of nature's strategies and nanoscientists' biomimetic attempts (see Ball 2002). Rather I would like to emphasize that the debate about the potentialities of nanotechnology basically boils down to the question 'what is a nanomachine?' However the notion of machine is itself polysemic, so that it can support dissimilar views of living systems and teach quite different lessons to nanoscientists and engineers.

\section{Machine: An all-pervading metaphor}

Over the past decades, the machine metaphor has invaded the language of biologists. In the early times of molecular biology, such metaphors were exclusively used for DNA transcription and translation. Nowadays each entity active in the cell is described as a machine: ribosomes are assembly lines, ATP synthases are motors, polymerases are copy machines, proteases and proteosomes are bulldozers, membranes are electric fences, and so on (Godsell 2003, Zhang 2003). Although biologists generally agree that living systems are the product of evolution rather than of design, they describe them as devices designed for specific tasks. Indeed, if biology can teach us about engineering and manufacturing, it is because the living cell is now viewed as a factory crowded with numerous bionanomachines in action.

At the same time, in chemistry and materials science, machine metaphors have also become prominent. One major objective of nanotechnology programs is to build nanomachines that will do a better job than conventional 
machines. As they seek to design functional materials, physicists and chemists readily redefine the product of their design as machines: wheelbarrow molecules, cantilever molecules, springs, and switches are specimens of the inventions commonly reported in materials journals.

Thus the languages of molecular biology and materials science remarkably converge in a stream of machine metaphors. Through a continuous process of mutual transfer of concepts and images, they have built a common paradigm based on an artificialist view of nature. Nature is populated with nanomachines that human technology should be able to mimic or even to surpass.

Drexler and other advocates of the nano revolution primarily find in molecular biology a reply to all nanoskeptics. The data of molecular biology is a chief argument about the feasibility of nanofabrication: ${ }^{2}$

One might doubt that artificial nanomachines could even equal the abilities of nanomachines in the cell, if there were reason to think that cells contained some special magic that makes them work. This is called vitalism. Biologists have abandoned it because they found chemical and physical explanations for every aspect of living cells yet studied, including their motion, growth, and reproduction.

Drexler thus rejuvenated the positivist crusade of $19^{\text {th }}$-century synthetic chemists like Marcellin Berthelot against the limits imposed by superstition or by the metaphysical belief in a vital force. The existence of life itself is the proof that nanomachines are feasible according to Marvin Minsky from the MIT Media Lab and AI Lab: ${ }^{3}$

It seems quite strange for anyone to argue that you cannot build powerful (but microscopic) machinery - considering that our very own cells prove that such machines can indeed exist. And then if you look inside your cells you will find smaller machines that cause disease. Most arguments against nanotechnologies are arguments against life itself.

From this quotation, it is clear that life provides more than just an invitation to build nanomachines; it rather constitutes an imperative. Life is a source of creativity, a legitimation of the enterprise as well as a reason to believe in its future.

In Drexler's view, nanotechnology is 'molecular manufacture'. The notion of molecular engineering is nothing new. As early as the 1950s, the term was used by a number of scientists who worked for the promotion of materials science and engineering (MSE) in American universities. Before the label 'MSE department' was adopted, this new branch was often referred to as 'molecular engineering'. ${ }^{4}$ What is specific about Drexler's program is the notion of manufacture, which conveys the vision of mass-production that will transform society. From the publication of his very first article in 1981, Drexler shifted from the notion of molecular engineering to that of manufacture. This early presentation of what could be a bottom-up process was clearly inspired by biology. 
Biochemical systems exhibit a 'microtechnology' quite different from ours: they are not built down from the macroscopic level but up from the atomic. Biochemical microtechnology provides a beachhead at the molecular level from which to develop new molecular systems by providing a variety of 'tools' and 'devices' to use and to copy. Building with these tools, themselves made to atomic specifications, we can begin on the far side of the barrier facing conventional microtechnology. [Drexler 1981, p. 5275]

The artificialist view of biological systems thus encouraged a project which focused on the imagination of small machines that could 'pick and place' and assemble pieces on the model of robots and assembly-lines in a car factory. A few years later, given the scale of operation, Drexler was embarked in the fiction of self-replicating assemblers which raised the prospect of myriads of nanoassemblers copying themselves and consuming all the resources of the earth. The now too familiar grey goo scenario was a direct and logical consequence of Drexler's choice of a manufacturing model. Although Drexler recently regretted his speculations on the grey goo, it is important to emphasize that for him engineering and technology basically consist in manufacturing. ${ }^{5}$

While the controversy raised by Drexler focused on the feasibility of universal assemblers, it became increasingly obvious that his opponents questioned the model of manufacture without rejecting the machine metaphor. Significantly, George Whitesides, a professor of chemistry at Harvard University, developed his argumentation against Drexler's molecular assemblers in a paper entitled 'The Once and Future Nanomachines' (Whitesides 2001). Whitesides contrasts human-made machines with natural machines but he never questions the machine metaphor.

Nanoscale machines already do exist, in the form of the functional molecular components of living cells - such as molecules of protein or RNA, aggregates of molecules, and organelles ('little organs') - in enormous variety and sophistication. The broader question of whether nanoscale machines exist is thus one that was answered in the affirmative by biologists many years ago. The question now is: What are the most interesting designs to use for future nanomachines? And what, if any, risks would they pose? [Whitesides 2001, p. 78]

Drexler's molecular manufacture is depicted as an old fashioned and outdated model that has to be replaced by a more modern and more fashionable model taken from living cells. Mimicking human-scale machines is both inadequate and inefficient given the constraints of fabrication at the nanoscale. By contrast, mimicking the simplest cellular nanomachines is a marvelous challenge.

In other terms, the dispute between Drexler and Whitesides seems to rest on two rival models of machinery. Both of them agree that nanotechnology should take inspiration from living organisms, but they part company when it comes to the ways of making those nanomachines. 


\section{Drexler's mechanical machines}

What is 'life' for Drexler and his colleagues of the Foresight Institute? From the outset, Drexler explicitly based his plan on a close comparison between biochemical components and the operating units of macroscopic machines as shown in his 1981 article (Table 1).

Table 1. Comparison of macroscopic and microscopic components (source: Drexler 1981).

\begin{tabular}{|c|c|c|}
\hline Technology & Function & Molecular example(s) \\
\hline Struts, beams, casings & $\begin{array}{l}\text { Transmit force, } \\
\text { hold positions }\end{array}$ & $\begin{array}{l}\text { Microtubules, cellulose, } \\
\text { mineral structures }\end{array}$ \\
\hline Cables & Transmit tension & Collagen \\
\hline Fasteners, glue & Connect parts & Intermolecular forces \\
\hline Solenoids, actuators & Move things & $\begin{array}{l}\text { Conformation-changing } \\
\text { proteins, actin/myosin }\end{array}$ \\
\hline Motors & Turn shafts & Flagellar motor \\
\hline Drive shafts & Transmit torque & Bacterial flagella \\
\hline Bearings & Support moving parts & Sigma bonds \\
\hline Containers & Hold fluids & Vesicles \\
\hline Pipes & Carry fluids & Various tubular structures \\
\hline Pumps & Move fluids & Flagella, membrane proteins \\
\hline Conveyor belts & Move components & $\begin{array}{l}\text { RNA moved by fixed } \\
\text { ribosome (partial analog) }\end{array}$ \\
\hline Clamps & Hold workpieces & Enzymatic binding sites \\
\hline Tools & Modify workpieces & $\begin{array}{l}\text { Metallic complexes, } \\
\text { functional groups }\end{array}$ \\
\hline Production lines & Construct devices & Enzyme systems, ribosomes \\
\hline Numerical control systems & Store and read programs & Genetic system \\
\hline
\end{tabular}

With struts, cables, fasteners, glue, motors, bearings, containers, pumps, and clamps, Drexler's living bodies are surprisingly reminiscent of Descartes' animal-machines. In both cases, the living machine is made of a set of independent pieces - a few building blocks - mechanically assembled by a designer. Drexler described molecules as rigid building blocks similar to the parts of tinker toys - whether they are Meccano or Lego construction sets. The functions performed by the various pieces of molecular machinery are also essentially mechanical. They position, move, transmit forces, carry, hold, store, etc. Although Drexler declared that his molecular manufacture is the extrapolation 
to the smallest scale - by a process of 'mental shrinking' of today's automated factories (Drexler 2001, p. 74), his automata look like Vaucanson's automata performing complex tasks thanks to an assembly of simple mechanisms. Drexler is fond of the metaphor of 'molecular hands' manipulating nanoobjects and placing them wherever they need to go to perform the desired function. Nanosystems are like factories engaged in a rigid framework of controlled motions using the building blocks of matter as raw materials.

As in Descartes' theory of animal-machines, the tasks to be performed by the nanomachine, i.e. the direction of its movements, are embedded by the designer in the mechanical devices. The assembly process itself is described with the metaphor of "mechanosynthesis" or "the use of mechanical control to guide the placement of molecules so as to build complex objects" (Drexler 1995, p. 6). The keyword is "molecular assembler". This is the magic wand that binds together the pieces in an arrangement allowing them to perform useful tasks. Molecular assemblers are "devices able to guide chemical reactions by positioning reactive molecules with atomic precision" (Drexler 2003b). They are neither specific nor individual molecules. They are described as universal, all-purpose assemblers that can assemble all kinds of materials in the same way that ribosomes can assemble all kinds of proteins.

We know that Drexler shaped his program of molecular manufacturing while he was a research affiliate at MIT Space Systems Laboratory then MIT Artificial Intelligence Laboratory, under the sponsorship of Marvin Minsky. It is therefore not unlikely that his program was influenced by cyberneticians' concepts. Although Drexler's references to von Neumann in Engines of creation is limited to his studies on self-replicating machines, he might also have borrowed his notion of 'universal assemblers' which were able to grab components out of their location and put them together according to programmed instructions. Similarly, Drexler's assemblers would move atoms, place them in the right position, and selectively bind them.

Drexler's program thus seems to combine two models of machines. On the one hand, his description of molecular manufacture rests on classical mechanics, requiring only space, matter, and motion. In this sense, his matter is like Boyle's uniform, catholic matter, deprived of spontaneity as well as of individuality. Molecular machines, like clock mechanisms, require the hands and the brain of a clock-maker. As Georges Canguilhem emphasized in a commentary on Cartesian mechanism, such mechanical machines are not deprived of finality: all the teleology is concentrated at the starting point, in the act of design; and it is naively anthropomorphic (Canguilhem 1952, pp. 113-4). Canguilhem characterized the teleology inherent in Cartesian mechanism as 'technological anthropomorphism' as opposed to 'political anthropomorphism'. On the other hand, Drexler implicitly refers to computational machines, but without facing the challenge of complexity that von Neumann clearly prophesized. ${ }^{6}$ 
A second major feature that Drexler retained from biological systems is that they operate under programmatic control. He consequently shaped "a world in which digital data can be used to control general-purpose machines that will put the fundamental building blocks of matter in place to build almost everything" (Drexler 1995, p. 17). The DNA-RNA system provides the code and the instructions for the machine to operate. Protein assembly works according to rigid instructions, in a clean and efficient manner. Drexler's molecular manufacture is described in stark contrast with chemical manufacture. Conventional chemical reactions are extraordinarily messy:

Chemists today make complex molecular structures by taking smaller pieces, putting them together, stirring, and hoping that they will fall together to make the right product. If you imagine trying to make an automobile by taking parts, putting them into a box, shaking, hoping that they will fall togteher to make a working machine, you will conclude that it is very useful to have robots or hands, or something like them involved in the process. [Drexler, 1995, p. 2]

Chemistry looks so primitive and dirty when compared to protein machines that Drexler wonders how chemists, lacking the "molecular hands with which to put the parts where they want them", have managed to achieve such remarkable things. In living things, then, Drexler finds a precious guide to improving chemical technologies. Enzymes are his favorite model of assemblers. "[Enzymes] assemble large molecules," he explains, "by 'grabbing' small molecules from the water around them, holding them together so that a bond forms." In this manner they assemble DNA, proteins, and many other biological items. It should therefore be possible to put them to work on metal ions or complex structures in order to wield molecules with the precision of programmed machines. However, if enzymes and proteins show the way to build nanomachines, they do not provide a perfect model for nanotechnology. Drexler proposes to use protein machines only for the first generation of nanomachines because they present serious flaws as engineering materials. The amino acids of which they are composed are simply not tough enough for the construction of nanomachines. Drexler's ambition is to mimic life's devices working under genetic instructions in order to build machines more robust than organisms.

Finally, Drexler borrowed a third concept from biology - evolution - in order to legitimize his program. Drexler advocates an evolutionary model of technological changes, presenting human technology as the continuation of natural evolution. Chapter 2 of Engines of Creation placed the emergence of molecular manufacturing in a grandiose picture starting with cosmic order out of chaos then gradually evolving towards organization, then replications, and technology. Evolutionary principles guide Drexler's foresight exercises. They are supposed to determine what paths are open and possible as well as the limits of technological achievements. Drexler thus uses evolutionary bi- 
ology in order to 'naturalize' the kind of technology that he encourages. In this respect he paved the way for Ray Kurzweil's prophecies of spiritual machines and universal intelligence.

For Ray Kurzweil, a staunch supporter of Drexler's program, and active promoter of Artificial Intelligence, nanotechnology is the means, but artificial intelligence is the end. Kurzweil uses evolutionary biology in order to 'naturalize' the kind of technology that he encourages. According to him, it is the evolution of life itself that tended to overcome the limitations of human brain by inventing computational technology and now presides over the building of nanobots. This vague notion of a process of hominization is all Kurzweil needs to establish himself as the prophet of a new era of spiritual machines. His argument rests on two postulates: (i) human technologies are the continuation of biological evolution; just as the flint chipper was an extension of the human hand, so the nanorobot extends the human brain; (ii) exponential growth is the feature of any evolutionary process of which technology is a primary example (Moore's law). The logical conclusion of this syllogism is this: the golden age of nanotechnology will come within a couple of decades as an unavoidable future. Because it is the continuation of the natural process of evolution, we have no choice over the matter. We must simply accept it and adapt our society to a world shared with nanobots.?

To sum up this section, Drexler and his supporters have developed a concept of machine that combines an old mechanistic model inherited from Cartesian mechanics - a passive matter moved by external agents - with a more recent computational model of machines inherited from cybernetics. Both the mechanistic model and the cybernetic one rest on the assumption of a blind mechanism operating without intentionality under the control of a program. Biological evolution itself is conceived of as a blind mechanism operated and controlled by an all-powerful algorithm.

\section{The Dynamic Model}

A quite different perspective is conveyed by the chemists who vigorously criticized Drexler's model of machine. George Whiteside's frequent use of the term 'art' in his papers on nanotechnology epitomizes their approach to the field. ${ }^{8}$ Nanostructures belong to 'art' both in the Aristotelian sense of technê, or design for specific purposes, and in the sense of skill, since they require the invention of astute and unconventional methods of nanofabrication. For chemists, the age of nanotechnology is not exactly a radical break. After all, building molecular architectures is what chemistry has done for many centuries and chemists took inspiration from living structures before 
the term nanotechnology became fashionable. In 1978, for example, bioinspiration led to the creation of a new branch of chemistry - supramolecular chemistry - whose aim is to obtain molecular recognition without the help of genetic code through chemical processes that mimic the selectivity of biological processes. According to Jean-Marie Lehn, who coined the term 'supramolecular chemistry', "it is one of the major chemist's motivation to see that biology successfully made highly complex properties on a molecular basis."

In their bio-inspiration, materials chemists are less concerned with genetic programs and genetic engineering than with the stuff of which living things are made. Their main purpose is to understand what is unique about biological materials both in their structure and in the dynamics of their development and morphogenesis. ${ }^{10}$ Living organisms are models for nanodesign first and foremost because they present materials adapted, by design, to a set of performances.

Like Drexler, materials scientists and engineers have shaped an artificialist view of nature. For them, biological evolution is a kind of engineer designing efficient systems. Unlike Drexler and Kurzweil, however, they assume that nature is an insuperable engineer. Nature is not so much a model of order as a model of ingeniosity (ingenium). It is a wizard, an astute designer playing tricks with nature's laws. For instance, Richard Smalley, who was awarded the Nobel Prize for the discovery of $\mathrm{C}_{60}$, describes the works of nature with superlative and playful terms:

Nature has played the game at this level [the nanoscale] for billions of years, building stuff with atomic precision. Every living thing is made of cells that are chok-full of nanomachines - proteins, DNA, RNA, etc. - each jiggling around in the water of the cell, rubbing up against other molecules, going about the business of life. Each one is perfect right down to the last atom. The workings are so exquisite that changing the location or identity of any atom would cause damage. [Smalley 1999]

In trying to understand the tricks used by nature to solve her 'engineering problems', materials chemists received three major lessons from biology.

First, biomaterials are interesting because they are never homogeneous. Whereas engineered materials are usually processed for a single property, biomaterials are multifunctional composite structures. The interest of material scientists, especially chemists working on high performance composites, is to learn something about the art of associating heterogeneous structures from nature itself. In their effort to design composite structures at the molecular level, they either turned their attention to such familiar materials as wood, bone, or mucus, or to mollusk shells, insect cuticles, spider-silk, etc. These composite structures - associating hard and soft, combining inorganic and organic components, and capable of high performance - appeared to be ideal models for human technology for various reasons. They are models of func- 
tional diversity, being adapted for a variety of tasks including growth, repair, and recycling. Unlike Drexler's machines with rigid parts each of them designed for one specific function, biological nanomachines may not be mechanically robust and they may not have optimal performances, but they offer a good compromise between properties for different environments. The key to success of living organisms does not lie in a single engineered building block that concentrates all the instructions or information for operating the machine. Rather, biology teaches chemists that success comes with improving the art of mixing heterogeneous components and working out elegant solutions to complex problems. Consequently, the focus is less on the ultimate components of matter than on the relations between them. Interfaces and surfaces are crucial because they determine the properties of the components of composite materials and how they work together. Nanochemistry distinguishes itself from the culture of purity and high vacuum chambers by advancing an impure process of composition and hybridization that mimics natural materials. Biology does not provide a model of highly concentrated information as suggested by Feynman's famous talk. It is a model of interaction and composition. Nature challenges nanomaterials scientists to design a composite displaying more properties than the sum of the properties of its components. In this case biology provides a model of emergence.

The major objections raised by Whitesides and Smalley concern Drexler's view of universal assemblers. Drexler saw in enzymes the model of universal assemblers, a sort of molecular hands capable of moving parts to the right position for assembly. This assertion has provoked the skepticism of chemists who are well aware of the constraints of atoms' reactivity. Smalley (2001) raised two objections: not only would 'molecular fingers' obviously take up too much space and prevent the closeness needed for reactions at the nanoscale (the 'fat fingers' problem); but they would also adhere to the atom being moved, making it impossible to move a building block where you want it to go (the 'sticky fingers' problem). Drexler replied to these objections in an open letter:

My proposal is, and always has been to guide molecular synthesis of complex structures by mechanically positioning reactive molecules, not by manipulating atoms. This proposal has been defended successfully again and again, in journal articles, in my MIT doctoral thesis [...] [Drexler 2003]

He complained that Smalley attempted to undermine his scientific credentials and that for positioning reactive molecules no computer-controlled "Smalley fingers" are required. Smalley responded by asking, "So, if the assembler doesn't use fingers, what does it use?" If there is some kind of enzyme or ribosome in self-replicating nanorobots, he reasoned, then there should be water inside because enzymes and ribosomes can only work in water where they find all the nutrients necessary for living systems. Since there is no possibility 
of fine chemistry without solvent, Smalley denied that nanorobots working in high-vacuum are chemically plausible. As Philip Ball (2003) noticed, "It is becoming increasingly clear that the debate about the ultimate scope and possibilities of nanotech revolves around questions of basic chemistry".

For Whitesides, Drexler's program to force chemical reactions by placing the reagents in the right position is useless. "Fabrication based on the assembler is not, in my opinion, a workable strategy and thus not a concern. For the foreseeable future, we have nothing to fear about the grey goo." (Whitesides 2001, p. 83) Materials chemists simply dismiss Drexler's scenario because their main objective is to dispense with assemblers, by self-assembly. The top of their 'art' consists in making heterogeneous components spontaneously converge in the right location and assemble into larger aggregates without any external intervention. In fact, neither manipulating the molecules nor programming the machines requires outside intervention because the components move by themselves. A fascinating perspective was opened up by George Whitesides (1995):

Our world is populated with machines, non living entities assembled by human beings from components that humankind has made [...] In the $21^{\text {st }}$ century, scientists will introduce a manufacturing strategy based on machines and materials that virtually make themselves; what is called self-assembly is easiest to define by what it is not. A self-assembling process is one in which humans are not actively involved, in which atoms, molecules, aggregates of molecules and components arrange themselves into ordered, functioning entities without human intervention [...] People may design the process, and they may launch it, but once under way it proceeds according to its own internal plan, either toward an energetically stable form or toward some system whose form and function are encoded in its parts.

To be sure, Whitesides provides here only a negative definition of selfassembly, but this does not mean that it would be an obscure process that chemists do not understand. Many processes are explored to make variants of nature's highly-directional self-assembly. Chemists use templates such as mesoporous silica or they conduct synthesis in compartments (Ball 2002, pp. 25-26). They take advantage of all possible resources of chemistry and thermodynamics in an effort to mobilize all sorts of interactions between atoms and molecules. Instead of using covalent bonds like traditional organic chemists, they make use of weak interactions such as hydrogen bonds, Van der Waals, and electrostatic interactions. They use microfluidics and surfactants in order to produce self-assembled monolayers which, in turn, permit them to move from atomic and molecular level structure to macroscopic property.

Self-assembly presupposes that the instructions for assembly are integral to the material components themselves or that they are embedded in their relations. Matter can no longer be viewed as a passive receptacle upon which in- 
formation is imprinted from the outside because self-assembly rests on spontaneous reactions between materials. Molecules have an inherent activity, an intrinsic dynamis allowing the construction of a variety of geometrical shapes (helix, spiral, etc.). It is not an obscure and mysterious vital force, a breath, or animus that would come from the outside to give life to inanimate matter. It is more like Claude Bernard's inner force guiding phenomena generated by physico-chemical causes. But ironically, it is the reductionist approach of molecular biology - the understanding of the mechanisms of molecular recognition as well as the process of morphogenesis - that eventually allowed chemists to develop such emergentist views of molecular architectures. ${ }^{11}$

A third contrast between the chemists' and Drexler's views of nanomachines resides in their attention to complexity. Here, this term is taken in a weak sense, referring to non-linear processes. Complexity became a problem when chemists started to examine the behavior of single molecules instead of dealing with Avogadro numbers of molecules. How do molecules cooperate to produce the average properties and behavior of familiar macroscopic chemicals, became a puzzling question (Whitesides \& Ismagilov 1999). In fact, chemists had suspected that nanoparticles behave differently than macroscopic chemical substances long before the coming of nanoscience. ${ }^{12}$ Gold, usually characterized by its yellow color, becomes red when processed in nanospheres. More generally, the color of metal and semiconductor nanoparticles depends on their size, a property commonly used in the glass industry. Today, it is also used to design magnetic materials with iron/platinum colloids, an application that has rendered colloid synthesis a highly sophisticated and promising domain of nanochemistry (Evans \& Wennerstrom 1999). Given this long-standing attention to size-sensitive properties, the discovery that the semi-conductor behavior of bulk graphite can be modified into metallic behavior according to the size and geometry of carbon nanotubes did not come as a revelation in theoretical chemistry. Chemists were prepared to admit that elements have special properties and behavior when processed at the nanoscale. Unlike computer scientists, who are eager to replicate conventional machines at the nanolevel, materials scientists focus mainly on size-sensitive properties. Their work comprises the entire hierarchy of structures in living systems, from large molecules that assemble at the nanoscale to form organelles, to cells, tissues, and organs that ultimately compose unique organisms. Therefore, they cannot rely on a uniform view of nature as being the same at all scales. While it is true that the laws of nature are universal, chemists do not assume that they apply equally to all scales.

To sum up, chemists working on the design of nanomaterials seem to rely on a specific underlying view of machines that revives a number of antimechanistic notions. They do not deprive matter of spontaneity or dynamis; instead of assembling prefabricated building blocks, they play with composi- 
tion and interfaces; instead of inferring from the macro to the nanoscales, they assume a hierarchy of structures. While Drexler's efforts are aimed at eliminating chemistry in order to work under the strict control of a program, they mobilize all possible resources of chemistry, of kinetics and thermodynamics.

\section{Historical roots}

Clearly engineers and chemists have two irreconcilable views of nanomachines. So striking is the contrast that it raises the question: are there two cultures within the field named nanotechnology? In their revolutionary claims, Drexler and his followers never mention earlier attempts at taking inspiration from life. His emphasis on the bottom-up approach creates a discontinuity with more traditional materials processes. Moreover, thanks to the reference to Feynman, nanotechnology seems to be rooted in quantum physics thus proceeding from a 'noble' theoretical science rather than from 'dirty' experimental physics or materials engineering. However this was not the first biomimetic. There had been many previous attempts at mimicking living organisms at the macro and the microlevels.

Biomimetism has been a leitmotif in technology from mythical attempts the wings of Daedalus - up to the more recent examples like velcro. In many technological areas, such as aeronautics, architecture, and textiles, mimicking living things has been a current practice that has lead to some brilliant results $^{13}$. Biomimetism is more than a handful of occasionally successful bioinspired inventions. It became a research program in the $20^{\text {th }}$ century initiated by Darcy Thompson, a zoologist who applied mathematics to the study of living shapes and physics to the study of their growth. In On Growth and Forms (1992 [1942]) he argued that the different parts of an organism are optimally shaped. This book was the root of a joint approach of living organisms by biologists and engineers. Bionics (literally, 'units of life') was an attempt to evaluate the efficiency of an organism or a machine, to measure the structures and processes by which the 'purposes' or ends of the system were fulfilled $^{14}$. In the postwar period, biomimetism benefited from strong support from the US army, Naval research, and the National Institute of Health. The term 'biomimesis' was introduced in 1961 at the second symposium on bionics by Warren S. McCulloch, a neuroscientist member of the Research Laboratory of Electronic at MIT, as a generic concept. Taking the term in its most extensive sense, "the imitation of one form of life by another", McCulloch (1962) included the mimetic strategies to avoid enemies or catching preys that are predetermined in the genes of insects. McCulloch divided biomimesis into two distinct fields, cybernetics and bionics. Cybernetics, he ar- 
gued, deals with control functions rather than with mechanical work. ${ }^{15}$ It is mainly concerned with regulation mechanisms and feedback control. By contrast, 'bionics' was defined "as an attempt to understand sufficiently well the tricks that nature actually uses to solve her problems, this enabling us to turn them into hardware" (ibid., p. 393). According to McCulloch the latter requires more than interdisciplinarity, new skills. He called for a novel science and a new organization of scientific research because: "one has to have a reasonable knowledge of both engineering and biology in his own head" for the purpose of understanding living systems. First he called logicians to join the program because new skills in logic and mathematics are necessary to understand the complex organization of living systems. Second, he called for increasing work on the thermodynamics of open systems because the major development that he saw coming was the understanding of natural processes that go on along with ever-increasing entropy: how order evolves from the inside instead of being forced upon a material after torturing it. In bionics the emphasis was on the holistic structure of living organisms. For instance, in an introductory paper entitled 'Bio-logic', Heinz von Foerster argued that the fundamental principle in life was 'coalition' rather than self-reproduction.

What I call coalition is an aggregate of elements which jointly can do things which all of them separately could never achieve. It is characterized by a superadditive nonlinear composition where the whole is more than the sum of the measure of the parts. [Foerster 1962]

Finally McCulloch identified a third, but minor trend of biomimesis: the design of artificial organisms that are capable of evolving and learning. At this time, it was just a small group interacting with the community, but it should become extremely fashionable in Materials Science and Engineering over the past decades. Materials scientists look at Nature as an insuperable designer of optimal, multi-functional, and self-repairing structures (Bensaude-Vincent et al. 2002). They are trying to understand 'the tricks that nature actually uses to solve her problems', and to mimic them in order to solve their own problems.

Beyond McCulloch's dual genealogy of biomimetism, the current divorce between two paradigms of nanotechnology resonates with an older philosophical problem. The current trend generates serious 'epistemological risks'. The mechanistic model may have a heuristic power for some time as it had, for instance, in the history of medicine. However, its epistemic relevance as a simplifying model may lead to epistemic obstacle because it ignores inner dynamics and power at work both in living organisms and in technological systems. Moreover, as George Canguilhem suggested in a paper on 'machine and organism', the mechanization of life is inseparable from a project of instrumentalization of life and control over nature. Descartes' theory of animalmachines rested on a systematic depreciation of animals in order to legitimize 
their utilization as tools by humans (Canguilhem 1952, p. 111). Ethical and epistemological issues are closely intertwined.

At this critical point, it may be helpful to go back to the ancient Greek notion of technê. ${ }^{16}$ It is well-known that, while Aristotle defined technê as a mimesis of nature, he did not hesitate to draw analogies from arts to describe nature as a craftsman displaying the ingeniosity associated with mechanics. There is nothing new in the current artificialization of nature. Already in antiquity, there were two different and occasionally conflicting views of technology. On the one hand, the arts or technai were considered as working against nature, as contrary to nature. This meaning of the term para-physin provided the ground for repeated condemnations of mechanics and alchemy. On the other hand, the arts - especially agriculture, cooking, and medicine were considered as assisting or even improving on nature by employing the dynameis or powers of nature. In the former perspective, the artisan, like Plato's deminrgos, builds up a world by imposing his own rules and rationality on a passive matter. Technology is a matter of control. In the latter perspective the artisan is more like the ship-pilot at sea. He conducts or guides forces and processes supplied by nature, thus revealing the powers inherent in matter. ${ }^{17}$ Undoubtedly the mechanicist model of nanotechnology belongs to the demiurgic tradition. It is a technology fascinated by the control and the overtaking of nature.

Nanotechnology and biotechnology are mainly concerned with the control of nature at the most basic level, i.e. the level of atomic building blocks. It does not really matter whether the control of the molecular machinery is in the hands of humans or in the hands of posthuman cyborgs. The grey goo scenario is just the continuation of a long tradition of mythologies and fictions - ranging from Prometheus to Faust and Frankenstein. Yet there remains an alternative future that could make nanotechnology more akin to agriculture or traditional medicine. Susan Linquist from MIT Whitehead Institute once said: "About 10,000 years ago, [humans] began to domesticate plant and animals. Now it's time to domesticate molecules." (quoted in Zhang 2003, p. 1177) In this case, blurring the boundary between life and matter invites neither reductionism nor dreams of control. On the contrary, nanoscientists dealing with isolated molecules cannot adopt the standard subject-object relation. Isolated molecules tend to become more like individuals or partners whom science and technology try to domesticate. If scientists and engineers were ready to behave more like farmers relying on plants and animals or like pilots in relying on winds to guide their sea boat, our future might be less tragic as it seems today. Sailors know that all journeys are risky, that their jobs require many precautions because they have to negotiate with natural elements, necessarily involving a good deal of uncertainties. 


\section{Notes}

1 A major source on this controversy is the special issue of Scientific American, September 2001. See also the open correspondence between Richard Smalley and Eric Drexler available on the website of the Foresight Institute; Chemical E Engineering Nerws, December 1, 2003, Vol. 81, No. 48, pp. 37-42

2 Drexler 1986, p. 17. See also the comment posted by Lenester on Mind X 04/17/2003 on Drexler's “An open letter to Richard Smalley” [www.kurzweilai. net/meme/frame.html]: The very idea that something which is clearly done in nature cannot also be done by us, is counter to the most basic spirit of science. It hearkens back to an age of magical descriptions, implying that there's some mystic Stuff out there which is beyond our mortal ken.

3 Minsky 1995, p. 193; Rietman 2001, p. 2.

4 For instance, as early as 1956, Arthur von Hippel, professor at MIT advocated an interdepartmental research center named 'molecular engineering'. The emerging discipline was aimed at designing new materials on the basis of molecular understanding. It comprised the structure, formation, and properties of atoms, molecules, ions, of gases, liquids, solids, and their interfaces. Electrical, magnetic, mechanical parameters were considered the most fundamental (MIT archives, AC 12, Box 71).

5 Nature, vol. 429, 10 June 2004, p. 591. See also Phoenix \& Drexler 2004.

6 Dupuy 2000. Drexler did his Ph.D. in Marvin Minski's laboratory, who wrote his doctoral thesis under von Neumann.

7 This is the conclusion of Kurzweil's Testimony quoted above. Technology has always been a double-edged sword, so we simply need to implement 'defensive technologies' against self-replicating nanobots in the same way as our society is defending itself against computer viruses. See also, Kurzweil 1998.

8 See for instance Whitesides 1998, Whitesides \& Love 2001.

$9 \quad$ Lehn 2004, see also Lehn 1995.

10 See for instance Sarikaya \& Aksay 1995.

11 Emergence here should be understood in thermodynamic terms as the production of higher order out of lower order, which according to Norbert Wiener was the major characteristics of machines and living organisms as well. Self-assembly is a process leading from less ordered to higher thermodynamically ordered ensembles of molecules or macromolecules. The resulting aggregates have new properties that could not have been predicted from the characteristics of individual components. A major difference lies in the fact that aggregates formed in a laboratory environment are in a state of equilibrium, whereas in living beings most of them are out of equilibrium.

12 This phenomenon was observed in metal colloids or hydrosols by Michael Faraday in the mid- $19^{\text {th }}$ century and became known as the 'Tyndall effect' after Tyndall extended Faraday's earlier observations. Suspended particles that are small relative to the wavelength of visible light (with radii of approximately $20 \mathrm{~nm}$ ) are brilliantly colored in red, green, and violet because the interaction with the incoming light is a combination of absorption and scattering (Arribart 2004, p. 363).

13 Vogel 1998, pp. 249-75. Among the most famous examples of successful copies are the Crystal Palace designed by Joseph Paxton whose roof allegedly copied a giant water lily; the spinneret for extruding textile fibers inspired by the organ of silkworms; barbed wire; and the velcro invented by the Swiss engineer Georges Mestral on the model of the hooked burs that clung to his socks. 
14 See for instance Howland 1962.

15 According to McCulloch, cybernetics emerged from the steam engine, when Julian Bigelow pointed out that it was only the information concerning the outcome of the previous act that had to return.

16 See for instance Schiefsky (forthcoming) and Staden (forthcoming).

17 On the contrast between the two definitions of technology in the case of genetically modified organisms, see for instance Larrère 2002.

\section{References}

Arribart, H.: 2004, 'Les nanomatériaux autres que ceux des technologies de l'information et des communications (TICS)', in: Académie des sciences, Académie des technologies (eds.), Nanosciences, nanotechnologies, éditions Tec \& Doc, Paris, pp. 361-382.

Ball, P.: 2002, 'Natural Strategies for the molecular engineer', Nanotechnology, 13, 15-28.

Ball, P.: 2003, 'Nanotechnology in the firing line', Nanotechweb.org, 23 December [http://www.nanotechweb.org/articles/society/2/12/1/1].

Bensaude-Vincent, B.; Arribart, B.Y.; Sanchez, C.: 2002, 'Chemists at the School of Nature', New Journal of Chemistry, 26, 1-5.

Canguilhem, G.: 1952, Machine et organisme' in La connaissance de la vie, Hachette, Paris [quoted from the fourth edition Vrin, Paris, 1971].

Drexler, K.E.: 1981, 'Molecular engineering: An approach to the development of general capabilities for molecular manipulation', Proceedings of the National Academy of Sciences, 78, no. 9, chemistry section, 5275-78.

Drexler, K.E.: 1986, Engines of Creation, Anchor Books, New York.

Drexler, K.E.: 1992, Nanosystems. Molecular machinery, manufacturing and computation, John Wiley \& Sons, New York.

Drexler K.E.: 1995, 'Introduction to nanotechnology', in: Krummenacker, M. \& Lewis, J. (eds.), Prospects in Nanotechology. Proceedings of the $1^{\text {st }}$ general conference on nanotechnology: developments, applications, and opportunities, November 1114, 1992, Palo-Alto, John Wiley \& Sons, New York, pp. 1-20.

Drexler, K.E.: 2001, 'Machine-Phase nanotechnology', Scientific American, (Sept.), 66-67.

Drexler, K.E.: 2003a, 'Open Letter', Chemical E Engineering News, 81, no. 48, 37-42.

Drexler, K.E.: 2003b, 'An open letter to Richard Smalley', April 16, [published on KurzweilAI.net].

Dupuy, J.P.: 2000, The Mechanization of the Mind, Princeton University Press, Princeton N.J.

Evans, D.F.; Wennerstrom, H.: 1999, The Colloidal Domain: Where Physics, Chemistry, Biology and Technology Meet, John Wiley \& Sons, New York.

Foerster, H.v.: 1962, 'Bio-Logic', in: E.E. Bernard \& M.R. Kare (eds.), Biological prototypes and synthetic systems, Plenum Press, New York, vol. 1., pp. 1-12

Godsell, D.: 2003, Living Machinery. Bionanotechnology: Lessons from Nature, WileyLiss, New-York.

Howland, H.: 1962, Structural, hydraulic and economic aspects of leaf venation and shape ', in: E.E. Bernard \& M.R. Kare (eds.), Biological prototypes and synthetic systems, Plenum Press, New York, vol. 1, pp. 183-192 . 
Kurzweil, R.: 1998, The Age of Spiritual Machines, How We Will Live, Work and Think in the New Age of Intelligent Machines, Phoenix, New York.

Larrère, R.: 2002, 'Agriculture: artificialisation ou manipulation de la nature?', Cosmpolitiques, 1 (June), 158-173.

Lehn, J.M., 2004: 'Une chimie supramoléculaire foisonnante', La lettre de l'Académie des sciences, 10, 12-13.

Lehn, J.M.: 1995, Supramolecular Chemistry, VCH, Weinheim.

McCulloch, W.S.: 1962, 'The imitation of one form of life by another - Biomimesis', in: E.E. Bernard \& M.R. Kare (eds.), Biological prototypes and synthetic systems, Plenum Press, New York, vol. 1., p. 393-97.

Minsky, M.: 1995, 'Virtual Molecular Reality', in: Krummenacker, M. \& Lewis, J. (eds.), Prospects in Nanotechology. Proceedings of the $1^{\text {st }}$ general conference on nanotechnology: developments, applications, and opportunities, November 11-14, 1992, Palo-Alto, John Wiley \& Sons, New York, pp. 187-205.

Phoenix, C.; Drexler, E.: 2004, 'Safe Exponential Manufacturing', Nanotechnology, 15, 869-72.

Rietman, E.A.: 2001, 'Drexler hypothesis of a universal assembler is supported not by theoretical arguments alone but by existence proof in the form of biological life', in: Molecular Engineering of Nanosystems, Springer, New York \& Berlin.

Sarikaya, M.; Aksay, I. (eds.), 1995, Biomimetics. Design and Processing of Materials, AIP Press, Woodbury, New York.

Schiefsky, M.J.: forthcoming, 'Art and Nature in Ancient Mechanics', in: W.R. Newman \& B. Bensaude-Vincent (eds.), The Artificial and the Natural: An Ancient Debate and its Modern Descendants, MIT Press, Cambridge, MA.

Smalley, R.E.: 1999, 'Prepared written statement and supplemental material', Rice University, 22 June [http//www.house.gov/science/smalley_062299.htm].

Smalley, R.E.: 2001, 'Of Chemistry, Love and Nanobots', Scientific American, (Sept.), 76-77.

Staden, H.v.: forthcoming, 'Physis and Technê in Greek Medicine', in: W.R. Newman \& B. Bensaude-Vincent (eds.), The Artificial and the Natural: An Ancient Debate and its Modern Descendants, MIT Press, Cambridge, MA.

Thompson, D.: 1992 [1942], On Growth and Forms, Cambridge University Press, Cambridge.

Vogel, S.: 1998, Cats' paws and catapults, Norton \& Cy, New York, London.

Whitesides G.: 1995, 'Self-Assembling Materials,' Scientific American, (Sept.), 146-9.

Whitesides G. 2001 'The Once and Future nanomachines', Scientific American, (Sept.), 78-83.

Whitesides, G.: 1998, 'Nanotechnology: Art of the Possible', Technology, MIT Magazine of Innovation, (Nov.-Dec.), pp. 8-13.

Whitesides, G.; Love, J.C.: 2001, 'The Art of Building Small', Scientific American, (Sept.), 38-47.

Whitesides, G.M.; Ismagilov, R.F.: 1999, 'Complexity in Chemistry’, Science, 284, 89-92.

Zhang, Shuguang (2003) 'Fabrication of novel biomaterials through molecular selfassembly', Nature Biotechnology, 21, no. 10, 1171-78

Bernadette Bensaude-Vincent:

Département de philosophie, Université Paris X, Avenue de la République 200, 92001 Nanterre Cedex, France; bensaude@u-paris10.fr 